\title{
O MUNDO ATLÂNTICO PELO PRISMA DA OPINIÃO PÚBLICA
}

\section{- Victor Bertocchi Ferreira*}

Universidade de São Paulo

São Paulo - São Paulo - Brasil

Resenha do livro: GROESEN, Michiel van. Amsterdam's Atlantic: Print Culture and the Making of Dutch Brazil. Philadelphia: University of Pennsylvania Press, 2017.

Em seu mais recente trabalho, o historiador neerlandês Michiel van Groesen dá sequência a seus estudos sobre a cultura impressa europeia referente à América e ao mundo atlântico. Se, em sua tese de doutoramento, o agora professor de História Marítima da Universidade de Leiden teve por objeto a publicação dos relatos de viagem e as estratégias editoriais da família De Bry (GROESEN, 2008), ${ }_{1}^{1}$ em Amsterdam's Atlantic: Print Culture and the Making of Dutch Brazil o autor escreve a história de como as ações militares, comerciais e evangelizadoras da Companhia das Índias Ocidentais (WIC) no Atlântico foram assimiladas pela população de Amsterdam, transformandose em objeto de acalorado debate público.

O termo Print Culture (Cultura Impressa) incluído no subtítulo não expressa, entretanto, a real dimensão do livro. As mídias impressas e as

\footnotetext{
Mestrando pelo Programa de Pós-Graduação em História Social do Departamento de História da Faculdade de Filosofia, Letras e Ciências Humanas da Universidade de São Paulo e bolsista da Fundação de Amparo à Pesquisa do Estado de São Paulo - FAPESP, processo 2016/21278-5). E-mail: victor.bertocchi@gmail.com.

1 O autor também editou o livro The Legacy of Dutch Brazil (GROESEN, 2014).
} 
práticas sociais a elas relacionadas representam, indubitavelmente, parcela substantiva do estudo de Groesen. Porém, a unidade de análise por meio da qual a história da ascensão e queda do "Brasil holandês" se apresenta em sua totalidade histórica é a da "opinião pública". O objetivo da obra é mostrar não apenas como o mundo atlântico invadiu os circuitos de informação e discussão de Amsterdam, mas também a maneira pela qual esses mesmos canais e a própria lógica do debate público impactaram os rumos dos acontecimentos atlânticos. Nas palavras do autor,

"Print may have initiated and stimulated popular interest in Brazil, but public opinion and its reflections in print ultimately determined how and why Dutch Brazil came to be 'Amsterdamnified"'. (GROESEN, 2017, p. 8).

Por esta razão, ao apresentar os argumentos de Amsterdam's Atlantic, o historiador ressalta mais uma vez a centralidade do conceito de opinião pública:

\footnotetext{
"By emphasizing public opinion, I therefore aspire to achieve two broader goals. First, I will demonstrate the relevance of Atlantic history for the Dutch Republic, in that information from across the ocean transformed opinion making at home in a way other colonial ventures had never done. And, second, I will demonstrate the relevance of the Dutch Republic for Atlantic history, urging scholars to look beyond the discourse of empire that has traditionally favored Spain and Britain (and to a lesser extent Portugal and France) and appreciate the crucial role of news, information, and public opinion in the making of the Atlantic world." (GROESEN, 2017, p. 9).
}

Que a unidade de análise de Amsterdam's Atlantic ultrapassa a cultura impressa podemos constatar também pela diversidade de fontes manejadas por Groesen. Nos primeiros capítulos, os argumentos são construídos sobretudo a partir dos "jornais" (newspapers) publicados semanalmente por Broer Jansz. e Jan van Hilten, além dos "mapas de notícias" (news maps, p. 51) comissionados pela WIC e produzidos por Claes Jansz. Visscher e Hessel Gerritsz. Porém, em função do aumento da presença neerlandesa no Atlântico e o vai-e-vem contínuo de soldados, marinheiros, ministros da Igreja Calvinista, mercadores, indígenas e africanos, o conjunto de testemunhas oculares das vicissitudes americanas fez ampliar as redes informais de comunicação, dilapidando a proeminência das mídias impressas. Por meio de cartas privadas, diários, um album amicorum, panfletos avulsos, sermões, poemas e até mesmo pelas petições dirigidas à WIC, o autor consegue inferir e mapear essas redes, fazendo-nos ver a importância das relações entre familiares, vizinhos e conhecidos, o poder do púlpito e os contatos travados na região portuária, nas tabernas, bordéis, hospedarias e imediações da Bolsa 
de Amsterdam. Atento aqui à junção entre história urbana e história da comunicação, o autor assim reconstitui espacialmente a arena de informação e discussão por meio da qual o Atlântico penetrava a cidade.

Os seis capítulos que compõem o livro organizam o enredo de uma forma ao mesmo tempo cronológica e temática, o que torna a leitura fluida e a compreensão do texto clara. Ao passo em que a história do "Brasil holandês" vista a partir de Amsterdam se desenrola, passando pelo gradual envolvimento da população com temas brasileiros, a celebração das primeiras vitórias, o crescimento das tensões e disputas, o jogo da "culpabilização" pela derrota e a rememoração da antiga colônia, Groesen nos apresenta os elementos que definem o engajamento da opinião pública com as matérias atlânticas. Nesse sentido, reflete-se, por exemplo, sobre os gargalos da comunicação entre Europa e América, responsáveis por formatar uma "cultura de antecipação" (culture of anticipation): a demora das notícias amplificava a expectativa da população, estimulando hábeis editores a prepararem livretos e panfletos para o imediato momento da confirmação das vitórias militares.

Outro aspecto diz respeito ao já citado aumento dos canais de informação sobre o Atlântico, que não só diminuía a primazia das mídias impressas tradicionais, como também facilitava a apropriação das matérias atlânticas por segmentos médios e baixos da população, conferindo-lhes capacidade de agência frente às instâncias que geriam a Companhia. Isso pode ser visto na maneira frequente com que mães, esposas e viúvas de soldados e marinheiros traziam demandas às reuniões da Câmara de Amsterdam (um dos cinco escritórios que compunham a administração da WIC). O relativo sucesso com que tais mulheres exigiam o pagamento dos soldos de seus familiares mostra o quão bem informadas mantinham-se pelas redes de comunicação existentes sobre o que ocorria do outro lado do oceano. A aparente preocupação em receber as demandas e, acima de tudo, aceitar os pedidos, revela, por sua vez, o cuidado dos diretores em manter a credibilidade da Companhia em alta.

As tentativas da WIC de criar um consenso público em torno das iniciativas coloniais no Brasil mostraram-se, a médio prazo, infrutíferas. Se nos primeiros anos, os esforços publicísticos da Companhia e a conjuntura de vitórias marítimas foram suficientes para manter um relativo "controle" do debate público, com a Insurreição Pernambucana (1645) e o crescente endividamento da empresa, antigas fraturas antes abafadas reapareceram com virulência em panfletos anônimos, mostrando que também o mundo Atlântico estaria sujeito à feroz "cultura de discussão" (discussion culture) de Amsterdam. Esse aspecto da opinião pública é sintetizado por Groesen 
através do neologismo Amsterdamnified (capítulo 5), termo retirado de um panfleto escrito pelo poeta inglês John Taylor em 1641. A expressão resume a maneira como o acirramento do debate público em Amsterdam poderia, por vezes, sair da esfera de controle das autoridades municipais, adquirindo uma dinâmica própria na qual escritores profissionais e editores, protegidos pelo anonimato, inflamavam a audiência urbana. Em defesa da colônia, panfletos acusavam de traição oficiais do exército, ou mesmo regentes de Amsterdam, pela alegada recusa de apoio à WIC. Folhetos contra os defensores da Companhia, em contrapartida, também se tornaram abundantes no período, criticando o estado calamitoso da Nova Holanda. O ano de 1649, em particular, experimentou o apogeu das praatjes (diálogos), gênero de panfletos impressos nos quais os temas cotidianos eram apresentados através da encenação de conversas entre figuras típicas locais.

Ao fim, a WIC perderia a batalha doméstica pela opinião pública, erodindo parte do que lhe restava do suporte político nas Províncias Unidas e apressando, segundo o autor, a queda de Recife. Os regentes de Amsterdam, justamente no momento em que a Companhia mais precisava de auxílio financeiro, recusaram-se a salvar a colônia em apuros. O abandono do "Brasil holandês" pela cidade teria, com efeito, um papel decisivo nos rumos da guerra luso-neerlandesa.

A perda da colônia americana não significou, todavia, o fim das representações sobre o Brasil nas Províncias Unidas. No sexto capítulo, Groesen apresenta quais imagens permaneceram vivas na memória coletiva dos neerlandeses. Impulsionando tal esforço de rememoração encontravase, em primeiro lugar, a própria campanha publicística levada a cabo pelo conde João Maurício de Nassau, que utilizaria o conjunto de pinturas, livros e utensílios referentes ao Brasil como capital político na corte de Haia. Ao lado das obras patrocinadas por Nassau, circulavam também no mercado neerlandês os quadros feitos por Frans Post após seu retorno a Haarlem. Os temas e motivos tropicais pintados nessa fase de sua carreira passariam a impulsionar uma imagem supostamente "exótica" do Brasil, em franco contraste com as representações do período de ocupação da colônia, detentoras de "elementos etnográficos" particulares ao impulso nassoviano. Finalmente, a imagem do Brasil permaneceria indiretamente presente na celebração dos almirantes da WIC. A partir da década de 1650, dá-se início nas Províncias Unidas àquilo que ficaria conhecido como o "culto aos heróis navais" (LAWRENCE, 1992). Livros e biografias coletivas sobre as principais batalhas e almirantes dariam grande espaço à rememoração de homens que fizeram sua fama no Atlântico, como Hendrick Loncq, Jan Lichthart, Joost Banckert 
e Jacob Willekens. Piet Heyn, o mais célebre de todos, se tornou conhecido não apenas pelo roubo da frota de prata (1628), mas também pelos ataques a Salvador em 1624 e 1627, sobre os quais desde a segunda metade do século XVII até a segunda metade do XIX seria produzida rica iconografia.

O argumento central de Amsterdam's Atlantic repousa no conceito que amarra o livro na Conclusão: a existência de um Atlântico Público durante o período moderno. Groesen quer com isso chamar atenção, em primeiro lugar, para o ávido interesse com que o Atlântico era acompanhado pelas audiências europeias. Vitórias e derrotas em pontos extremos do oceano repercutiam no circuito de informações e nos espaços de debate público, mostrando que a matéria atlântica havia se transformado em elemento da cultura política europeia. Mas, no caminho inverso, o autor mostra pelo exemplo do "Brasil holandês" como a cultura de discussão e o acirramento do debate público mantinham estreita relação com os rumos dos acontecimentos atlânticos. As opiniões defendidas calorosamente nos circuitos de discussão tinham a capacidade de influenciar os agentes e instituições engajadas nas tarefas coloniais: o Atlântico transformava-se, assim, em opinião veiculada na praça pública, impactando as respostas com que estados e companhias europeias reagiam aos desafios imperiais.

"Contemporaries in Amsterdam (and possibly elsewhere in Europe) realized that their own opinions might help consolidate or change the course of Atlantic developments. This not only raised the stakes of public debate in early modern Europe but also raises the significance of a 'public Atlantic' for the field of Atlantic history." (GROESEN, 2017, p. 194).

Embora o livro se coloque como um estudo sobre História Atlântica - o que sem dúvida alguma é -, o conceito de Atlântico Público tal qual formulado por Groesen não é operativo para todo o mundo atlântico. Vale lembrar que o livro fornece um estudo de caso que, segundo o autor, poderia ser extrapolado para outras comunidades políticas europeias, para as quais o Atlântico também teria relevância enquanto matéria de discussão pública. Que todos os exemplos se refiram às sociedades europeias se explica pela própria unidade de análise subjacente ao estudo:

"The making of news and opinion on Dutch Brazil was an exclusively European affair." (GROESEN, 2017, p. 4).

Com efeito, Groesen mostra implicitamente como a compreende e quais os limites de sua aplicação: o resultado, ao fim, é que embora o Atlântico seja público, o público que discute mediante opiniões não é atlântico, mas exclusivamente europeu. 
A história do ocaso da WIC e do "Brasil holandês", contada a partir da opinião pública de Amsterdam, pode por vezes tornar opacas algumas das grandes tensões políticas entre grupos e frações de classe que operavam por trás de panfletos anônimos. Em alguns momentos do livro - sobretudo no capítulo 5 - a ênfase dada à lógica do debate público - em particular a seus aspectos editoriais - acaba por relegar a um plano secundário as forças sociopolíticas rivais à WIC, que possivelmente manejaram de forma ativa tais canais. Veja-se por exemplo o ciclo de diálogos anônimos publicados em 1649 contra a Companhia, o qual Groesen limita-se a classificar como uma "poderosa campanha midiática emanada de Amsterdam", sem questionar especificamente qual ou quais grupos poderiam ter de fato se engajado nessa polêmica. ${ }^{2}$ Os "diálogos" de 1649 servem, para o autor, como exemplo da citada "Amsterdamnização" do debate público. Mesmo com a dificuldade advinda da natureza das fontes arroladas - escritos anônimos -, o leitor perde a referência dos interesses econômicos e geopolíticos subjacentes. Com efeito, a dilapidação da credibilidade da WIC parece ter sido obra apenas dessa lógica do debate público e de seus "profissionais". ${ }^{3}$

A crítica, porém, em nada reduz a qualidade e relevância de Amsterdam's Atlantic, uma vez que a grande questão de fundo da investigação de Groesen - ponto candente dentro da historiografia da colonização europeia no Novo Mundo - gira em torno do impacto que a colonização das Américas teve para os rumos das sociedades europeias. Vale lembrar que John Elliot, em The Old World and the New: 1492-1650 - um dos primeiros a elaborar a questão em seus contornos precisos -, havia minimizado o poder do Novo Mundo como re-

\footnotetext{
2 "a powerful media campaign emanating from Amsterdam throughout 1649." (GROSEN, 2017, p. 138). Há dois aspectos importantes na maneira como o autor lida com a questão. De um lado, a disputa é descrita como uma luta entre Zelândia e Amsterdam, sem levar em conta os grupos econômicos que, na maior cidade holandesa, apoiavam a Companhia. Por outro, a ênfase na "Amsterdamnização" do debate, promovida por uma mídia impressa sem sujeitos ou grupos concretos, nubla os interesses em jogo. "In the second half of the 1640s, the print media exploited the polarization to an extent that public discussion on Brazil could be conducted only by anonymous authors and printers whose addresses and names did not exist. At the same time, their rhetoric concretely named and shamed public figures such as Amsterdam burgomasters and the local directors of the West India Company or used stereotypically ordinary citizens to castigate the corrupted regent class." (GROESEN, 2017, p. 156, grifo nosso).

3 Como não pensar no paralelismo entre o que se discute no capítulo 5 e os acontecimentos que marcaram o ano de 2016 na Inglaterra e nos Estados Unidos? Sem embargo da distância entre o século XVII e o mundo contemporâneo, a aproximação dos dois contextos pode ter ao menos uma importante valia: tanto quanto a lógica dos canais de discussão, importa investigar a participação furtiva de agentes com desigual capacidade de intervir nos debates públicos.
} 
ferência cultural ao Velho. No início dos anos 2000, o estudo de Benjamin Schmidt, que assim como Groesen parte da experiência colonial neerlandesa do século XVII, já respondia ao problema em novos termos, apontando a importância da América e dos americanos como referência fundamental na construção do discurso político neerlandês durante a Guerra dos Oitenta Anos (SCHMIDT, 2006). A originalidade de Groesen é enfrentar o problema por meio de uma outra unidade de análise - até então pouco explorada nos estudos sobre o mundo atlântico -, desafiando, mais uma vez, a ideia de que o impacto da América na Europa teria sido menor ou tardio.

As contribuições de Amsterdam's Atlantic ultrapassam, portanto, o campo historiográfico do "Brasil holandês", colocando-se no ponto de intersecção entre História Atlântica e História Moderna. O livro apresenta um rico conjunto de evidências que sustentam as teses propostas, comprovando, assim, a importância das notícias atlânticas para a cultura política europeia.

\section{Referências bibliográficas}

GROESEN, Michiel van. The Representations of the Overseas World in the De Bry Collection of Voyages (1590-1634). Leiden \& Boston: Brill, 2008.

GROESEN, Michiel van. The Legacy of Dutch Brazil. Cambridge: Cambridge University Press, 2014.

GROESEN, Michiel van. Amsterdam's Atlantic: Print Culture and the Making of Dutch Brazil. Philadelphia: University of Pennsylvania Press, 2017.

LAWRENCE, Cynthia. "Hendrick de Keyser's Heemskerk Monument: The Origins of the Cult and Iconography of Dutch Naval Heroes". Simiolus: Netherlands Quarterly for the History of Art, Vol. 21, No. 4, 1992, p. 265-295.

SCHMIDT, Benjamin. Innocence Abroad. The Dutch Imagination and the New World, 1570-1670. Cambridge: Cambridge University Press, 2006.

Recebido: 05/04/2018 - Aprovado: 25/06/2018

Editores responsáveis pela publicação:

Iris Kantor e Rafael de Bivar Marquese. 